\title{
Identification of Cerebrospinal Fluid MicroRNAs Associated With Leptomeningeal Metastasis From Lung Adenocarcinoma
}

\begin{abstract}
Zhenyu Pan ${ }^{1,2,3 t}$, Guozi Yang ${ }^{2,3 t}$, Hua He ${ }^{4}$, Pengxiang Gao ${ }^{2}$, Tongchao Jiang ${ }^{2}$, Yong Chen ${ }^{1 *}$ and Gang Zhao ${ }^{1 *}$

${ }^{1}$ Department of Neuro-Oncological Surgery, The First Hospital of Jilin University, Changchun, China, ${ }^{2}$ Department of Radiation-Oncology, The First Hospital of Jilin University, Changchun, China, ${ }^{3}$ VA Palo Alto Health Care System, Stanford University Medical School, Palo Alto, CA, United States, ${ }^{4}$ Cancer Center, The First Hospital of Jilin University, Changchun, China
\end{abstract}

OPEN ACCESS

Edited by:

Jose Ramon Pineda,

University of the Basque

Country, Spain

Reviewed by:

Maya Jeitany

Nanyang Technological

University, Singapore

Yilong Zou,

Memorial Sloan Kettering Cancer

Center, United States

*Correspondence:

Yong Chen

chen_yong@jlu.edu.cn

Gang Zhao

gzhao@jlu.edu.cn

tThese authors have contributed equally to this work

Specialty section:

This article was submitted to

Neuro-Oncology and Neurosurgical

Oncology,

a section of the journal

Frontiers in Oncology

Received: 15 December 2019

Accepted: 04 March 2020

Published: 03 April 2020

Citation:

Pan Z, Yang G, He H, Gao P, Jiang T,

Chen Y and Zhao G (2020)

Identification of Cerebrospinal Fluid

MicroRNAs Associated With

Leptomeningeal Metastasis From

Lung Adenocarcinoma.

Front. Oncol. 10:387.

doi: 10.3389/fonc.2020.00387
Background: Leptomeningeal metastasis $(L M)$ has frequently been observed in patients with lung adenocarcinoma. So far, its diagnosis and disease course monitoring are still extremely difficult. Moreover, there is no effective treatment regimen for $L M$ due to a lack knowledge on the molecular mechanism of LM. This study aimed to identify LM-related cerebrospinal fluid (CSF) miRNAs, which have potential value for diagnosing and monitoring LM and exploring the molecular mechanism.

Methods: CSF miRNAs were screened and verified by microarray analysis and quantitative real-time PCR (qRT-PCR) in LM patients with lung adenocarcinoma and non-LM controls, and the diagnostic performance of candidate miRNAs was evaluated. Then, candidate miRNAs in matched CSF samples from LM patients at diagnosis, after initial therapy, at relapse, and after salvage therapy, were analyzed to assess the relationship between CSF miRNAs and LM disease course. The effect of candidate miRNAs on proliferation, invasion, and migration of lung adenocarcinoma cell lines was assessed. The targeted genes of the candidate miRNA were predicted by TargetScan, miRDB, and miRTarbase online analysis tools. Gene ontology (GO) and Kyoto Encyclopedia of Genes and Genomes (KEGG) were used to analyze the functional categories of predicted target genes.

Results: CSF miR-7975, miR-7977, and miR-7641 were screened and verified to be statistically significantly up-regulated in LM patients compared to non-LM controls. The three miRNAs, when combined, exhibited optimal diagnostic performance. Longitudinal data of CSF miR-7975 and miR-7977 correlated well with clinical courses of LM. Overexpression of miR-7977 promoted proliferation, migration, and invasion of lung adenocarcinoma cells. Moreover, 385 targeted genes of miR-7977 were predicted and were involved in various pathways related to cancer metastasis.

Conclusions: This study offers insights for future research of CSF miRNAs as robust tools for diagnosing and monitoring LM. It also reveals a novel pathway for exploration of underlying mechanisms of LM.

Keywords: leptomeningeal metastasis, cerebrospinal fluid, microRNA profiling, lung adenocarcinoma, bioinformatic analysis 


\section{INTRODUCTION}

Leptomeningeal metastasis (LM) is known as a devastating cancer complication that occurs when malignant cells disseminate to leptomeninges and cerebrospinal fluid (CSF) compartments (1-3). About $10 \%$ of patients with metastatic cancer suffer from LM during their course of the disease (4). Lung cancer is one of the most common causes of LM (5), of which adenocarcinoma accounts for $84-96 \%$ (6). Incidence is increasing in lung adenocarcinoma patients because of improved survival from new molecular targeted therapies (7). However, the diagnosis and disease course monitoring for LM are still challenging. Moreover, there is no effective treatment regimen for LM from lung adenocarcinoma due to lacking understanding of the molecular mechanism of LM.

MicroRNAs (miRNAs) are a group of noncoding RNAs, which can degrade messenger RNA (mRNA) and inhibit protein translation based on complementation with sequence of the target mRNAs (8). Through this approach, the altered expression of specific miRNAs is associated with cell proliferation, apoptosis, differentiation, and other biological processes (9). Moreover, it was known that some miRNAs were related to the occurrence and development of major diseases including nervous system diseases and cancers $(10,11)$.

CSF is a readily reachable body fluid and the most informative biofluid regarding changes that occur in the central nervous system (CNS) (12). The profiling of CSF miRNA expression indicated that specific miRNAs were related to CNS malignancies. It offers a powerful approach to understanding the development of CNS malignancies from the earliest manifestations to the terminal stages, and also provides insights about biology genetic changes of disease that might help to detect and monitor disease, as well as to explore the molecular features of the underlying malignancy (13). Over the past decades, miRNAs have been discovered to be involved in cancer metastasis (14). However, researches exploring LM-related miRNAs based on large-scale human CSF samples are rarely seen.

In this study, we first screened specific miRNAs by comprehensive miRNA microarray analyses in CSF samples from LM patients and non-LM controls, as well as in matched CSF samples from LM patients at diagnosis and after LM-directed therapy. Using quantitative real-time PCR (qRT-PCR), we then validated the expression of candidate miRNAs in CSF samples from independent LM patients with lung adenocarcinoma, and evaluated their diagnostic performance for discriminating LM patients from non-LM subjects. Next, we evaluated the effect of candidate miRNAs on proliferation, migration, and invasion of lung adenocarcinoma cell lines. The online analysis tools including TargetScan, miRDB, and miRTarbase were used to predict potential target genes of the candidate miRNA. Gene

\footnotetext{
Abbreviations: LM, leptomeningeal metastasis; CSF, cerebrospinal fluid; miRNAs, microRNAs; CNS, central nervous system; GO, gene ontology; KEGG, Kyoto Encyclopedia of Genes and Genomes; EANO-ESMO, European Association for Neuro-Oncology and European Society for Medical Oncology; GEO, Gene Expression Omnibus; AUC, area under curve; ROC, Receiver Operating Characteristic; MRI, Magnetic Resonance Imaging; PCBP1, poly(rC) binding protein 1; BBB, blood-brain barrier; BCSFB, blood-cerebrospinal fluid barrier.
}

ontology (GO) and Kyoto Encyclopedia of Genes and Genomes (KEGG) were used to analyze the functions of predicted target genes. The present study aimed to investigate LM-related miRNAs and their potential value in disease diagnosis and monitoring, and to explore the possible molecular mechanisms based on experimental validation and bioinformatic analysis.

\section{METHODS}

\section{Patients, CSF Samples, and Study Design}

In total, we collected $186 \mathrm{CSF}$ samples from three groups of participants: LM patients with lung adenocarcinoma, brain metastasis patients with lung adenocarcinoma, and non-cancer controls at the First Hospital of Jilin University, China, between September 2014 and December 2018. All samples were distributed to discovery and validation sets. Detailed clinical data are summarized in Tables 1, 2.

In the discovery phase, we performed comprehensive miRNA microarray analysis in CSF samples from $10 \mathrm{LM}$ patients with lung adenocarcinoma and 10 non-LM controls (5 brain metastases from lung adenocarcinoma and 5 non-cancers). Meanwhile, matched CSF samples collected from $6 \mathrm{LM}$ patients at diagnosis and after efficacious LM-directed therapy were also analyzed by miRNA microarray. MiRNAs differentially expressed in common between the two comparative models

TABLE 1 | Characteristics of LM patients with lung adenocarcinoma and non-LM controls of all sets.

\begin{tabular}{|c|c|c|}
\hline & $\begin{array}{l}\text { Discovery set } \\
(N=20)\end{array}$ & $\begin{array}{l}\text { Validation set } \\
(N=116)\end{array}$ \\
\hline \multicolumn{3}{|l|}{ Categories } \\
\hline $\begin{array}{l}\text { LMs with lung } \\
\text { adenocarcinoma }\end{array}$ & 10 & 68 \\
\hline \multicolumn{3}{|l|}{ Non-LMs } \\
\hline $\begin{array}{l}\text { BMs with lung } \\
\text { adenocarcinoma }\end{array}$ & 5 & 43 \\
\hline Non-cancers & $\begin{array}{l}5 \text { ( } 2 \text { cesarean sections } \\
\text { and } 3 \text { appendicitis) }\end{array}$ & $\begin{array}{l}5 \text { (1 cesarean section } \\
\text { and } 4 \text { appendicitis) }\end{array}$ \\
\hline \multicolumn{3}{|l|}{ Gender } \\
\hline Female & 13 & 66 \\
\hline Male & 7 & 50 \\
\hline Age median (range) & 52 years (28-73) & 54 years $(30-70)$ \\
\hline \multicolumn{3}{|c|}{ Neurological symptoms and signs } \\
\hline Yes & 9 & 87 \\
\hline No & 11 & 29 \\
\hline \multicolumn{3}{|l|}{ CSF cytology } \\
\hline Positive & 10 & 56 \\
\hline Negative & 10 & 60 \\
\hline \multicolumn{3}{|l|}{ Neuroimaging (MRI) } \\
\hline Positive for LM & 9 & 49 \\
\hline No evidence of LM & 6 & 62 \\
\hline Not performed & 5 & 5 \\
\hline
\end{tabular}

$L M$, leptomeningeal metastasis; $B M$, brain metastasis; CSF, cerebrospinal fluid; MRI, magnetic resonance imaging. 
TABLE 2 | Characteristics of six LM patients enrolled for paired CSF analyses in discovery set.

\begin{tabular}{|c|c|c|c|c|c|c|c|}
\hline $\begin{array}{l}\text { Patient } \\
\text { no. }\end{array}$ & Age (year) & Gender & $\begin{array}{l}\text { Neurological } \\
\text { symptoms and signs }\end{array}$ & CSF cytology & MRI abnormalities & $\begin{array}{l}\text { Systemic treatment } \\
\text { for primary tumor } \\
\text { before LM }\end{array}$ & LM-directed treatment \\
\hline I & 46 & Female & Headache & Positive & $\begin{array}{l}\text { Nodular/linear } \\
\text { enhancement }\end{array}$ & Chemotherapy & $\begin{array}{l}\text { WBRT with concurrent } \\
\text { intrathecal MTX }\end{array}$ \\
\hline$\|$ & 37 & Male & $\begin{array}{l}\text { Dizziness, } \\
\text { headache, nausea, } \\
\text { vomiting }\end{array}$ & Positive & $\begin{array}{l}\text { Nodular/linear } \\
\text { enhancement }\end{array}$ & Chemotherapy & $\begin{array}{l}\text { WBRT with concurrent } \\
\text { intrathecal Ara-c }\end{array}$ \\
\hline III & 62 & Female & $\begin{array}{l}\text { Dizziness, } \\
\text { hearing loss, tinnitus }\end{array}$ & Positive & Nodular enhancement & Icotinib & $\begin{array}{l}\text { WBRT with concurrent } \\
\text { intrathecal MTX }\end{array}$ \\
\hline IV & 49 & Female & $\begin{array}{l}\text { Headache, nausea, } \\
\text { visual disturbance, } \\
\text { seizures }\end{array}$ & Positive & Nodular enhancement & $\begin{array}{l}\text { Chemotherapy } \\
\text { Erlotinib }\end{array}$ & $\begin{array}{l}\text { WBRT with concurrent } \\
\text { intrathecal MTX }\end{array}$ \\
\hline V & 52 & Male & $\begin{array}{l}\text { Dizziness, } \\
\text { headache, nausea, } \\
\text { vomiting }\end{array}$ & Positive & linear enhancement & Erlotinib & $\begin{array}{l}\text { WBRT with concurrent } \\
\text { intrathecal MTX }\end{array}$ \\
\hline $\mathrm{Vl}$ & 50 & Female & Headache, vomiting & Positive & Nodular enhancement & Icotinib & $\begin{array}{l}\text { WBRT with concurrent } \\
\text { intrathecal Ara-c }\end{array}$ \\
\hline
\end{tabular}

LM, leptomeningeal metastasis; CSF, cerebrospinal fluid; MRI, magnetic resonance imaging; MTX, methotrexate; Ara-c, cytarabine; WBRT, whole brain radiotherapy.

of miRNA microarray were determined as candidate miRNAs. Subsequently, candidate miRNAs were quantified in CSF samples from an independent validation cohort including $68 \mathrm{LM}$ patients and 48 non-LM controls (43 brain metastases from lung adenocarcinoma and 5 non-cancers).

To investigate if candidate miRNAs were involved in the disease course of LM, 22 matched CSF samples were collected and analyzed at diagnosis and after efficacious initial therapy, as well as 8 sequential CSF samples were collected and analyzed at four time points: at diagnosis, after efficacious initial therapy, at relapse, and after salvage therapy. Detailed clinical data are summarized in Table 3.

The diagnosis of lung adenocarcinoma was confirmed by histopathology. The non-cancer controls were patients without cancerous disease who underwent lumbar anesthesia prior to the necessary surgery. The diagnosis of LM for patients enrolled in this study was based on positive CSF cytology or suggestive clinical and neuroimaging findings meeting the diagnosis criteria recommended by European Association for Neuro-Oncology and European Society for Medical Oncology (EANO-ESMO) Clinical Practice Guidelines (6). Recurrence and progression were ascertained by at least three neuro-oncologists referring to the following conditions: (1) the deterioration of neurological symptoms/signs was progressive, typically associated with LM for more than 1 week; (2) increased intracranial pressure $>300$ $\mathrm{mmH}_{2} \mathrm{O}$ and/or CSF glucose $<2.3 \mathrm{mmol} / \mathrm{L}$; (3) positive CSF cytology; (4) LM-related neuroimaging findings were worsening. Meanwhile, treatment-related side effects and other diseases that may lead to the above conditions should be excluded. The evaluation criteria for clinical response to LM-directed treatment were established on the improvement of neurologic symptoms/signs, CSF, and neuroimaging according to EANOESMO Clinical Practice Guidelines (6).

LM CSF samples in this study were from patients enrolled in the following clinical trials: ChiCTR-OOC-14005403,
NCT03082144, NCT03101579, and NCT03507244. Written informed consents were obtained from all participants, which indicated willingness to donate their CSF samples for research. The study received approved from Institution Ethics Committee of the First Hospital of Jilin University and in accordance with the principles of the Declaration of Helsinki. Permission to access and publish patient information was obtained from each of the patients.

\section{CSF Collection and Preparation}

The CSF samples from LM patients were collected at the time of diagnostic lumbar puncture or intrathecal chemotherapy. For brain metastasis patients with lung adenocarcinoma who were suspected of suffering LM but ultimately excluded, CSF samples were obtained by diagnostic lumbar puncture. The CSF samples of non-cancer controls were collected at the time of lumbar anesthesia prior to the necessary surgery. At least $2 \mathrm{ml}$ of each CSF sample was stored in aliquots within $1 \mathrm{~h}$ after collection at $-80^{\circ} \mathrm{C}$ until further processing. The blooded CSF samples were excluded.

\section{miRNA Expression Profiling Using Microarray Analysis}

Microarray analysis was performed using Agilent Human miRNA $\left(8^{*} 60 \mathrm{~K}\right)$ arrays. The microarray contains probes for 2,549 human miRNAs from miRbase v21.0. The miRNA molecules were labeled using the miRNA Complete Labeling and Hyb Kit from Agilent, following the manufacturer's standard protocol. Each slide was hybridized with 100 ng Cy3-labeled RNA using miRNA Complete Labeling and Hyb Kit (Cat \# 5190-0456, Agilent technologies, USA) in hybridization oven at $55^{\circ} \mathrm{C}$ for $20 \mathrm{~h}$. After hybridization, slides were washed in staining dishes (Cat \# 121, Thermo Shandon, USA) with Gene Expression Wash Buffer Kit (Cat \# 5188-5327, Agilent technologies, USA). Then slides were scanned by Agilent Microarray Scanner 
TABLE 3 | Characteristics of LM patients with lung adenocarcinoma for serial analyses of CSF miRNAs.

\begin{tabular}{|c|c|c|c|c|c|c|c|c|c|}
\hline Patient no. & Age (year) & Gender & $\begin{array}{l}\text { Neurological } \\
\text { symptoms and signs }\end{array}$ & $\begin{array}{l}\text { CSF } \\
\text { cytology }\end{array}$ & MRI abnormalities & $\begin{array}{l}\text { Systemic treatment } \\
\text { for primary tumor } \\
\text { before LM }\end{array}$ & Initial LM-directed treatment & $\begin{array}{l}\text { Interval between } \\
\text { initial LM } \\
\text { diagnosis and } \\
\text { relapse }\end{array}$ & $\begin{array}{l}\text { LM salvage } \\
\text { treatment }\end{array}$ \\
\hline 1 & 53 & Female & $\begin{array}{l}\text { Headache, visual } \\
\text { disturbance, seizures }\end{array}$ & Positive & Negative & None & $\begin{array}{l}\text { WBRT with concurrent intrathecal } \\
\text { MTX }\end{array}$ & & \\
\hline $2^{*}$ & 39 & Male & Dizziness & Positive & $\begin{array}{l}\text { Nodular/Linear } \\
\text { enhancement }\end{array}$ & Crizotinib, lorlatinib & $\begin{array}{l}\text { WBRT with concurrent intrathecal } \\
\text { Ara-c }\end{array}$ & 9.6 months & $\begin{array}{l}\text { Intrathecal } \\
\text { pemetrexed }\end{array}$ \\
\hline $3^{*}$ & 38 & Female & $\begin{array}{l}\text { Dizziness, } \\
\text { headache, nausea, } \\
\text { vomiting }\end{array}$ & Positive & Linear enhancement & Icotinib, Osimertinib & $\begin{array}{l}\text { WBRT with concurrent intrathecal } \\
\text { MTX; intrathecal Ara-c }\end{array}$ & 14.4 months & $\begin{array}{l}\text { Intrathecal } \\
\text { pemetrexed }\end{array}$ \\
\hline 4 & 60 & Male & $\begin{array}{l}\text { Dizziness, } \\
\text { headache, diplopia, } \\
\text { memory loss }\end{array}$ & Positive & $\begin{array}{l}\text { Nodular/Linear } \\
\text { enhancement }\end{array}$ & $\begin{array}{l}\text { Chemotherapy } \\
\text { Gefitinib }\end{array}$ & $\begin{array}{l}\text { WBRT with concurrent intrathecal } \\
\text { Ara-c }\end{array}$ & & \\
\hline 5 & 57 & Female & Cranial nerve palsies & Negative & Linear enhancement & Crizotinib & $\begin{array}{l}\text { WBRT with concurrent intrathecal } \\
\text { Ara-c }\end{array}$ & & \\
\hline 6 & 50 & Female & $\begin{array}{l}\text { Headache, nausea, } \\
\text { vomiting }\end{array}$ & Positive & Nodular enhancement & Chemotherapy & $\begin{array}{l}\text { WBRT with concurrent intrathecal } \\
\text { Ara-c }\end{array}$ & & \\
\hline $7^{*}$ & 37 & Female & $\begin{array}{l}\text { Dizziness, headache, } \\
\text { vomiting }\end{array}$ & Positive & Linear enhancement & Icotinib, Osimertinib & $\begin{array}{l}\text { WBRT with concurrent intrathecal } \\
\text { MTX; intrathecal Ara-c }\end{array}$ & 8.2 months & $\begin{array}{l}\text { Intrathecal } \\
\text { pemetrexed }\end{array}$ \\
\hline 8 & 47 & Male & Dizziness, headache & Positive & $\begin{array}{l}\text { Nodular/Linear } \\
\text { enhancement }\end{array}$ & Gefitinib & $\begin{array}{l}\text { WBRT with concurrent intrathecal } \\
\text { pemetrexed }\end{array}$ & & \\
\hline 9 & 52 & Female & $\begin{array}{l}\text { Dizziness, } \\
\text { headache, diplopia }\end{array}$ & Positive & Negative & $\begin{array}{l}\text { Icotinib, } \\
\text { Chemotherapy }\end{array}$ & $\begin{array}{l}\text { WBRT with concurrent intrathecal } \\
\text { pemetrexed }\end{array}$ & & \\
\hline 10 & 59 & Female & $\begin{array}{l}\text { Dizziness, headache, } \\
\text { diplopia, hearing loss }\end{array}$ & Positive & Linear enhancement & Gefitinib & $\begin{array}{l}\text { WBRT with concurrent intrathecal } \\
\text { pemetrexed }\end{array}$ & & \\
\hline 11 & 61 & Female & Conscious disturbance & Negative & $\begin{array}{l}\text { Nodular/Linear } \\
\text { enhancement }\end{array}$ & Afatinib & $\begin{array}{l}\text { WBRT with concurrent intrathecal } \\
\text { pemetrexed }\end{array}$ & & \\
\hline $12^{*}$ & 57 & Female & $\begin{array}{l}\text { Conscious disturbance, } \\
\text { headache }\end{array}$ & Positive & Linear enhancement & $\begin{array}{l}\text { Chemotherapy, } \\
\text { Icotinib, } \\
\text { Osimertinib }\end{array}$ & $\begin{array}{l}\text { WBRT with concurrent intrathecal } \\
\text { MTX; intrathecal Ara-c }\end{array}$ & 13.2 month & $\begin{array}{l}\text { Intrathecal } \\
\text { pemetrexed }\end{array}$ \\
\hline 13 & 66 & Female & None & Positive & Nodular enhancement & Osimertinib & $\begin{array}{l}\text { WBRT with concurrent intrathecal } \\
\text { Ara-c }\end{array}$ & & \\
\hline $14^{*}$ & 47 & Female & Headache, seizures & Positive & Linear enhancement & $\begin{array}{l}\text { Gefitinib, Icotinib, } \\
\text { Osimertinib }\end{array}$ & $\begin{array}{l}\text { WBRT with concurrent intrathecal } \\
\text { MTX; intrathecal MTX }\end{array}$ & 38.4 months & $\begin{array}{l}\text { Intrathecal } \\
\text { pemetrexed }\end{array}$ \\
\hline 15 & 61 & Female & $\begin{array}{l}\text { Dizziness, headache, } \\
\text { vomiting, conscious } \\
\text { disturbance }\end{array}$ & Positive & $\begin{array}{l}\text { Nodular/Linear } \\
\text { enhancement }\end{array}$ & None & $\begin{array}{l}\text { WBRT with concurrent intrathecal } \\
\text { Ara-c/MTX }\end{array}$ & & \\
\hline 16 & 52 & Male & $\begin{array}{l}\text { Dizziness, } \\
\text { headache, vomiting }\end{array}$ & Positive & Linear enhancement & Erlotinib & $\begin{array}{l}\text { WBRT with concurrent intrathecal } \\
\text { MTX }\end{array}$ & & \\
\hline $17^{\star}$ & 49 & Female & $\begin{array}{l}\text { Dizziness, } \\
\text { vomiting, seizures }\end{array}$ & Positive & $\begin{array}{l}\text { Nodular/Linear } \\
\text { enhancement }\end{array}$ & $\begin{array}{l}\text { Gefitinib, Icotinib, } \\
\text { Osimertinib, } \\
\text { Chemotherapy }\end{array}$ & $\begin{array}{l}\text { WBRT with concurrent intrathecal } \\
\text { MTX }\end{array}$ & 9.8 months & $\begin{array}{l}\text { Intrathecal } \\
\text { pemetrexed }\end{array}$ \\
\hline
\end{tabular}




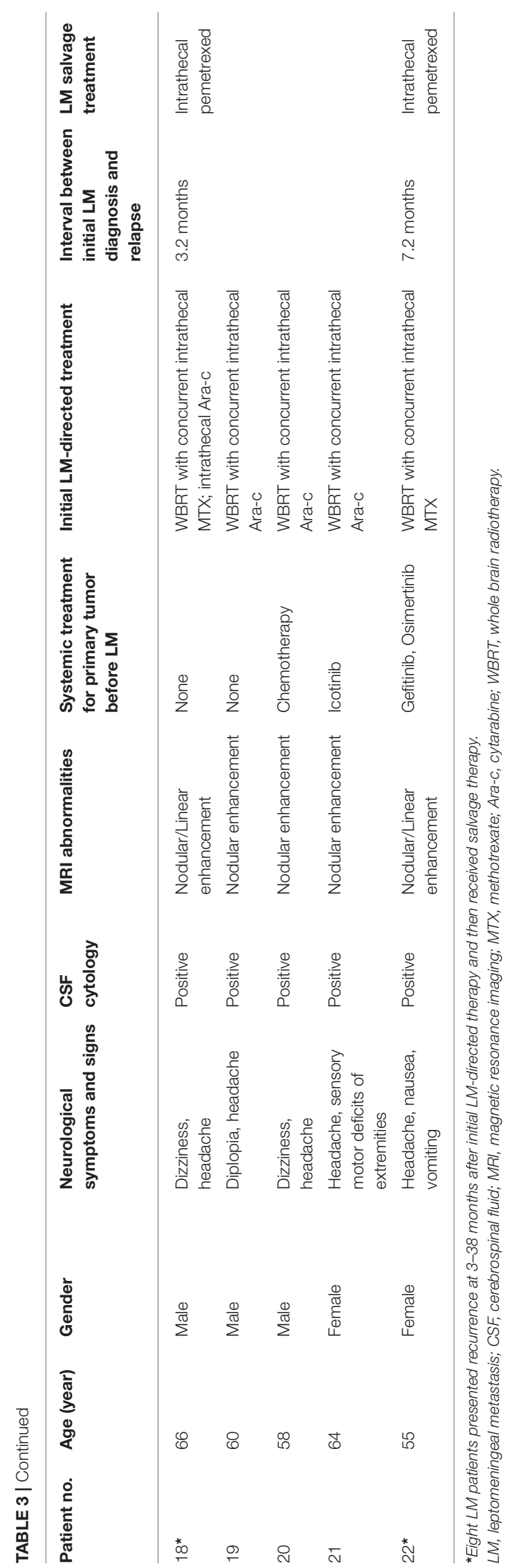

(Cat \# G2565CA, Agilent technologies, USA), and the images were processed with Feature Extraction software 10.7 (Agilent technologies, USA) with default settings.

\section{Cell Lines and Cell Transfection}

The human lung adenocarcinoma cell lines NCI-H1650 and A549, kindly provided by the First Hospital of Jilin University (Changchun, China), were cultured in RPMI-1640 Medium (Cat \# R8758, SIGMA, USA) and Dulbecco's Modified Eagle's Medium (DMEM; Cat \# D6429, SIGMA, USA), respectively, supplemented with $10 \%$ fetal bovine serum (FBS; Cat \# 010101, Trinity Tek, Spain), $100 \mathrm{U} / \mathrm{ml}$ penicillin, and $100 \mathrm{mg} / \mathrm{ml}$ streptomycin (Cat \# P4333, SIGMA, USA) in a humidified incubator at $37^{\circ} \mathrm{C}$ in a $5 \% \mathrm{CO}_{2}$ atmosphere.

Cells were seeded in six-well plates $\left(2 \times 10^{5}\right.$ cells per well $)$ overnight prior to transfection. MiRNA mimics $(50 \mathrm{nM})$ and negative control $(50 \mathrm{nM})$ were transfected into the cells by Lipofectamine 3000 reagent (Cat \# L3000015, Invitrogen, USA) in accordance with the manufacturer's instruction. The miRNA mimics and mimic negative control were purchased from GenePharma Co., Ltd (Shanghai, China).

\section{RNA Extraction and Quantitative Real-Time Polymerase Chain Reaction Analysis}

Total RNA from CSF samples was extracted and purified using QIAamp Circulating Nucleic Acid Kit (Cat \# 55114, QIAGEN, USA), following the manufacturer's instructions and checked for an RNA integrity number to inspect RNA integration by an Agilent Bioanalyzer 2100 (Agilent technologies, USA). For lung adenocarcinoma cells, total RNA was extracted using miRcute miRNA isolation kit (Cat \# DP501, Tiangen Biotech Co., Ltd, Beijing, China) at $24 \mathrm{~h}$ after transfection with miRNA mimics or negative control nucleotides.

Then miRNA was reverse transcribed with miScriptII RT Kit (Cat \# 218161, QIAGEN, USA), and quantified by qRTPCR using the miScriptSYBR ${ }^{\circledR}$ Green PCR Kit (Cat \# 218073, QIAGEN, USA) and commercial primers (hsa-miR-7975, hsamiR-7977, miR-7641, miR-4800-5p, QIAGEN, USA). All samples were run in triplicate on Line Gene 9600 Plus system (Bioer Techonogy, Hangzhou, China) using default settings. C. Elegans miR-39 (cel-miR-39, primer from QIAGEN, USA) in CSF samples and U6 (primer from Ribobio Co. Ltd, Guangzhou, China) in cell lines were used for control. The relative expression level (REL) of each miRNA in CSF samples and cell lines was calculated with the $2^{-\Delta \mathrm{Ct}}$ and $2^{-\Delta \Delta \mathrm{Ct}}$ methods, respectively.

\section{Cell Proliferation Assay}

At $24 \mathrm{~h}$ after transfection with miRNA mimics and negative control, cells were seeded into 96-well plates at a density of $5 \times 10^{3}$ per well. After incubation for another 12, 24, and 48 h, 10\% Cell Counting Kit-8 (CCK-8; Cat \# GK10001, GLPBIO, Montclair, CA, USA) diluted in normal culture medium was added to each well and incubated for an additional $4 \mathrm{~h}$. The absorbance was measured spectrophotometrically at $450 \mathrm{~nm}$. Each experiment was performed at least three times independently. 


\section{Wound Healing Assay}

The changes in cell migration ability were detected by wound healing assay. Cells were seeded in six-well plates. At $24 \mathrm{~h}$ after transfection with miRNA mimics or negative control, wounds were made in the cell layer using a sterile micropipette tip. Then, the cells were washed with PBS buffer. The width of the wound gap was viewed under a microscope and photographed at 0,9 , and $24 \mathrm{~h}$ after wounding. Three replicate wells from a six-well plate were used for this experiment.

\section{Cell Invasion Assay}

The invasion assay was performed with a transwell chamber inserted with a Polyester (PET) filter membrane $(8 \mu \mathrm{M}$ pores, Corning, USA) in 24-well plates (Corning, USA). The top side of the filter was coated with Matrigel. At $24 \mathrm{~h}$ after transfection with mimics or negative controls, the cells $\left(1 \times 10^{5} / \mathrm{ml}\right)$ were collected and resuspended in $200 \mu \mathrm{l}$ serum-free medium and added to the top well. Six hundred milliliter medium containing 15\% FBS was added to the lower compartment. After $48 \mathrm{~h}$ of incubation, the cells on the upper surface of the membrane were carefully removed with a cotton bud. The cells that invaded through the PET filter membrane were fixed with cold methanol for $30 \mathrm{~min}$, stained with $0.1 \%$ crystal violet for $20 \mathrm{~min}$, then photographed and counted under a microscope.

\section{Prediction of Target Genes}

The potential target genes of the differentiated expressed miRNAs are predicted using TargetScan, miRDB, and miRTarbase online analysis tools. The overlapping target genes were identified using Venn diagram in order to further enhance the bioinformatics analysis reliability.

\section{Gene Ontology and KEGG Pathway Analysis}

The functional annotation and pathway enrichment analysis including GO and KEGG pathway analysis $(15,16)$ were performed for the predicted overlapping target genes of the differentiated expressed miRNAs using database for annotation, visualization, and integrated discovery (DAVID, https://david. ncifcrf.gov). The criteria of cut-off were gene count $\geq 3$.

\section{Statistical Analysis}

GraphPad Prism (version 7.0, GraphPad Software) and SPSS (version 22.0, SPSS Software) were used for all statistical analyses. The data were expressed as mean \pm standard deviation (SD). Differential expression of miRNAs was analyzed by the unpaired T-test, Mann-Whitney test, and Wilcoxon matchedpairs signed rank test. A value of $P<0.05$ was regarded as statistically significant. Receiver operating characteristic (ROC) curve analysis was used to evaluate diagnostic performance.

\section{RESULTS}

\section{Profiling of CSF miRNAs in Leptomeningeal Metastasis Patients}

To evaluate whether specific miRNA signatures were detectable in CSF samples from LM patients with lung adenocarcinoma, a microarray analysis of 2,549 human miRNAs was performed. The criterion of each mappable miRNA was chosen for further analysis based on differentially expressed gene analysis with fold change values of more than 2 and $<0.5$. Based on the criteria described, 36 miRNAs upregulated and 15 miRNAs downregulated consistently in LM when compared with brain metastasis and non-cancer controls, respectively, were identified for further analysis (Figures 1A,B and Supplemental Table 1). The raw miRNA data are available from the NCBI Gene Expression Omnibus (GEO) through series accession number GSE125193.

In order to screen specific miRNAs correlated with the development of LM, we also performed miRNA microarray in CSF samples of six LM patients at diagnosis and their matched CSF samples after efficacious LM-directed therapy. Compared with the levels at diagnosis, CSF miR-7975, miR-7977, and miR4800-5p were significantly decreased after efficacious therapy (Figure 1C and Supplemental Table 2). The raw miRNA data are available from the NCBI GEO through series accession number GSE125193. As we have confirmed that the three miRNAs were significantly upregulated in LMs compared with non-LMs, the results indicate that the three miRNAs may be involved with the development of LM and, therefore, were selected for further validation. In addition, CSF miR-7641 with the largest foldchange value of 58.3 in LMs vs. non-LMs was also selected as a candidate miRNA.

\section{Validation of Candidate CSF miRNAs and Evaluation of Their Diagnostic Performance}

The robustness of the miRNA microarray data was studied by analyzing their levels using qRT-PCR in an independent validation set, which includes CSF samples from an additional $68 \mathrm{LM}$ patients with lung adenocarcinoma and 48 non-LM controls. MiRNA expression data were normalized using celmiR-39 levels in individual CSF specimens and reported as RELs. In concordance with the results presented in the discovery set, we found a significant difference for miR-7975, miR-7977, and miR-7641 between CSF samples from LM patients and nonLM controls (Figures 2A-C). However, for miR-4800-5p, we didn't observe the consistent result with microarray analysis (Figure 2D).

To demonstrate the utility of candidate CSF miRNAs in discriminating cases of LM with lung adenocarcinoma from non-LM subjects, ROC curve analysis was performed among the validation set. The results showed that the area under curve (AUC) value for miR-7975, miR-7977, and miR-7641 were $0.893(P<0.0001,95 \%$ CI $0.832-0.953), 0.867(P<$ $0.0001,95 \%$ CI $0.803-0.931)$, and $0.766(P<0.0001,95 \%$ CI $0.682-0.850$ ), respectively (Figures 2E-G). The diagnostic sensitivity and specificity were 88.24 and $83.33 \%$ for miR$7975,76.47$, and $87.50 \%$ for miR-7977, and $50.00 \%$ and $91.67 \%$ for miR-7641. Compared with miR-7641, both CSF miR-7975 and miR-7977 with AUC values of more than 0.85 exhibited better diagnostic performance in delineating LMs from nonLM subjects. In addition, the combined three miRNAs exhibited 


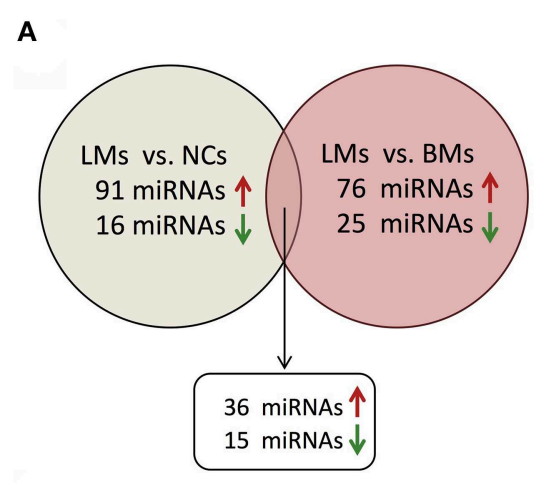

$\mathbf{B}$

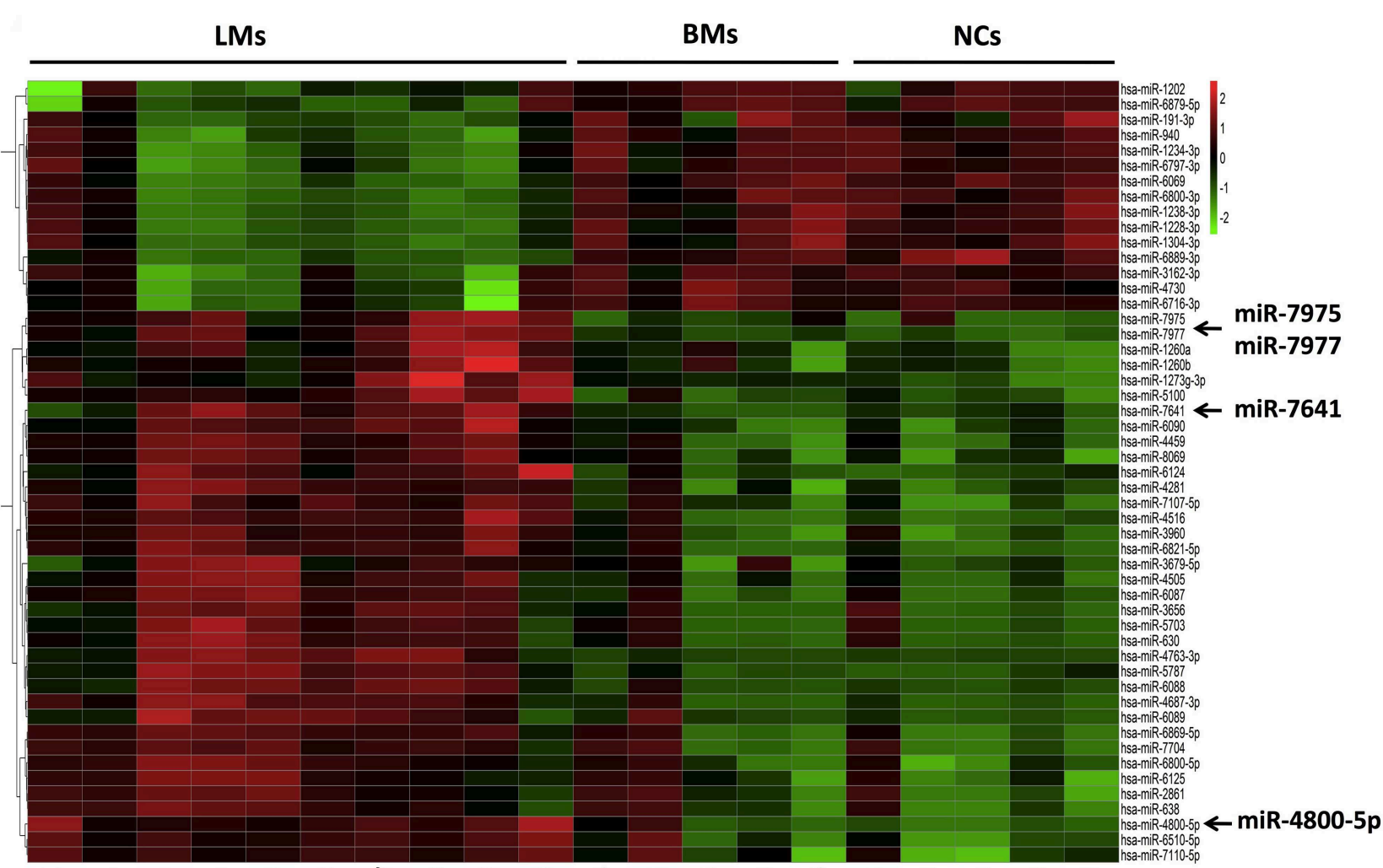

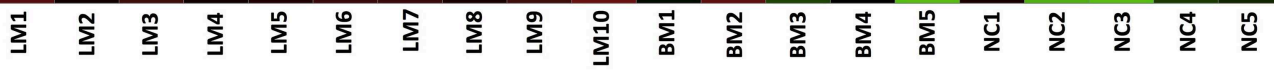

C

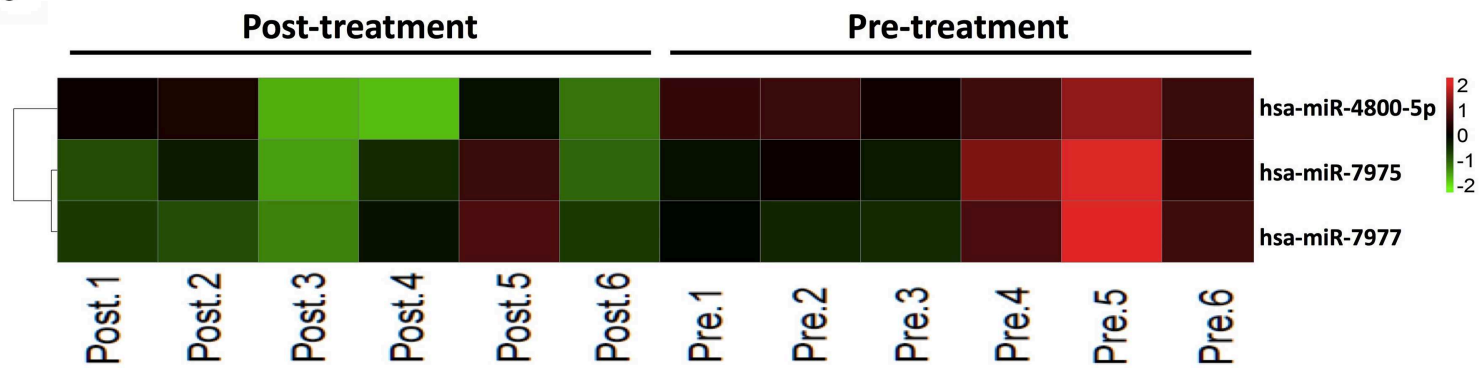

FIGURE 1 | Differential expression of miRNAs in CSF from discover cohort. (A) The overlapping miRNAs differentially expressed between two comparison models (LMs, $n=10$; BMs, $n=5$; NCs, $n=5$ ); (B) Heatmap of differentially expressed CSF miRNAs analyzed by microarray between LMs ( $n=10$ ) and non-LMs controls (BMs, $n=5$; NCs, $n=5$ ); (C) Heatmap of differentially expressed miRNAs analyzed by microarray in paired CSF samples from 6 LM patients at diagnosis and after initial LM-directed therapy. Fold change $\geq 2$ or $\leq 0.5$ was regarded as statistically significant. CSF, cerebrospinal fluid; LMs, leptomeningeal metastases; BMs, brain metastases; NCs, non-cancers. 

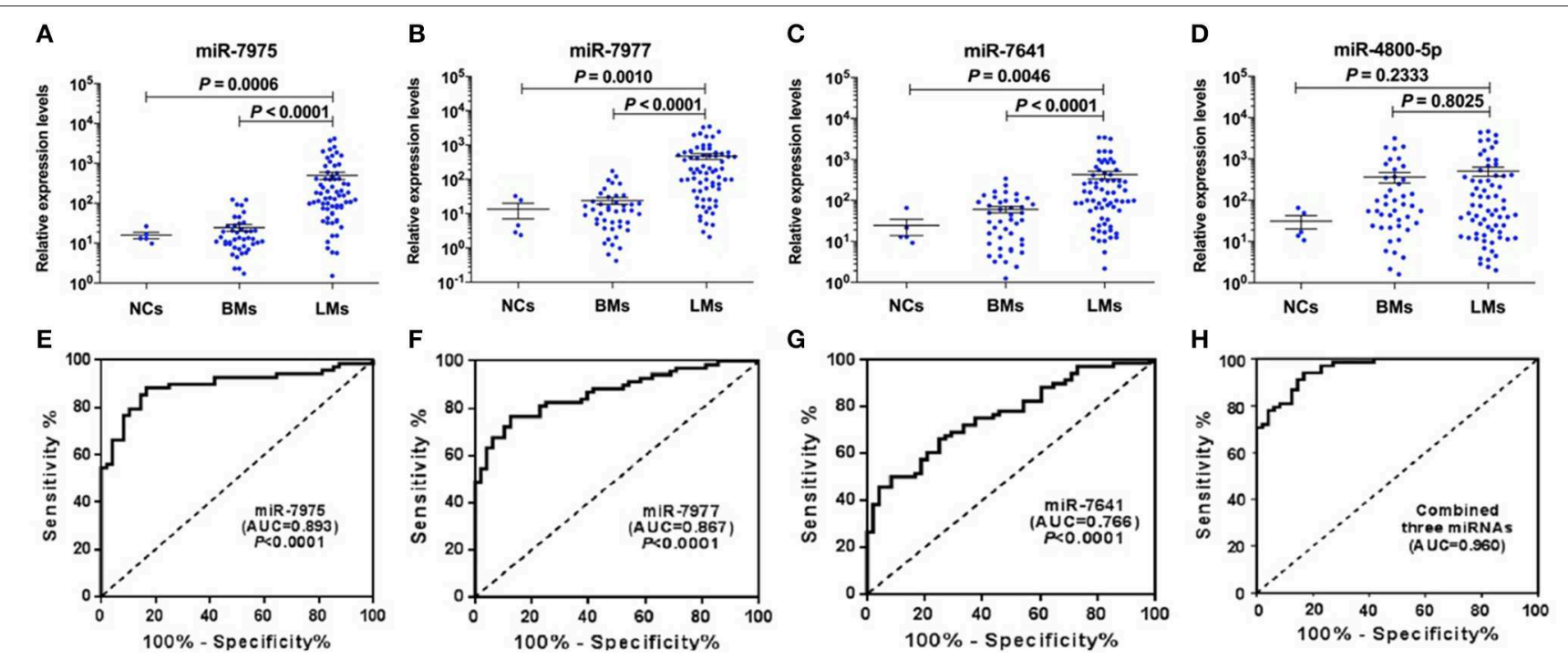

FIGURE 2 | Validation of candidate CSF miRNAs and evaluation of their diagnostic performance in validation cohort. RELs of CSF miR-7975 (A), miR-7977 (B), miR-7641 (C), and miR-4800-5p (D) in 68 LM patients vs. 48 non-LM controls (BMs, $n=43$; NCs, $n=5$ ) were detected by qRT-PCR. Then ROC curve analysis with RELs of CSF miRNAs including miR-7975 (E), miR-7977 (F), miR-7641 (G), and the combined three CSF miRNAs (H), was performed for discrimination of LMs and non-LM controls. RELs of miRNAs (y-axis) are normalized to cel-miR-39. The black horizontal lines represent median REL values with SEM. A value of $P<0.05$ was regarded as statistically significant. RELs, relative expression levels; LMs, leptomeningeal metastases; BMs, brain metastases; NCs, non-cancers; SEM, standard error of mean; AUC, area under curve.

the best performance in distinguishing LM cases from non-LM subjects with an AUC value of 0.960 (95\% CI 0.930-0.989), 94.10\% sensitivity, and $83.33 \%$ specificity (Figure $2 \mathbf{H}$ ). These data strongly indicated that CSF miRNAs may become reliable diagnostic markers for LM with lung adenocarcinoma.

\section{Identification of Candidate CSF miRNAs Expression Through the Course of Leptomeningeal Metastasis}

To observe the relationship between candidate CSF miRNAs expression and disease course, longitudinal studies were performed. RELs of the three miRNAs (miR-7975, miR-7977, and miR-7641) were compared in CSF samples of $22 \mathrm{LM}$ patients at initial diagnosis with their matched CSF samples after efficacious LM-directed therapy. Compared with the levels at diagnosis, CSF miR-7975 and miR-7977 were significantly down-regulated in LM patients after initial efficacious therapy (Figures 3A,B), while CSF miR-7641 was not (Figure 3C). To further investigate if levels of specific CSF miRNAs could be used to monitor the disease course, sequential CSF samples from eight LM patients were collected at four time points: at diagnosis, after initial therapy, at relapse, and after salvage therapy. Strikingly, longitudinal REL data of both CSF miR-7975 and miR-7977 in six out of eight LM patients correlated well with the clinical courses of LM (Figures 3D,E), decreasing after initial therapy, rising during relapse, and returning to lower levels after salvage LM-directed therapy. Although these observations are based on individual cases, these data support the application value of CSF miRNA levels for monitoring of disease course in LM.

\section{In vitro Effects of miR-7975 and miR-7977 on Proliferation, Migration, and Invasion of Lung Adenocarcinoma Cells}

In the first place, the expression levels of miR-7975 and miR7977 in NCI-H1650 and A549 cells after transfected with miRNA mimics at final concentrations of $50 \mathrm{nM}$ were detected using qRT-PCR (Figure 4A). To assess the effect of miR-7975 and miR-7977 on the proliferation of NCI-H1650 and A549 cells in vitro, we transfected the cells with $50 \mathrm{nM}$ miRNA mimics or negative control nucleotides. The CCK-8 assay showed that overexpressing miR-7977 increased the proliferation of NCIH1650 and A549 cells at 24 and $48 \mathrm{~h}$, while transfection with miR-7975 did not affect cell proliferation (Figure 4B). Then, a wound healing assay was performed to determine the roles of miR-7975 and miR-7977 in cells migration. As shown in Figure 4C, images of cell migration were obtained at the edge of the scratch at 0,9 , and $24 \mathrm{~h}$. After $24 \mathrm{~h}$, the wound gap was markedly closer in the miR-7977 mimic groups than in the negative control groups. The results suggested that miR-7977 promoted the motility of NCI-H1650 and A549 cells in vitro. However, overexpression of miR-7975 could not significantly affect cell migration, when compared with negative control cells. Next, we investigated the effect of miR-7975 and miR7977 on the invasion of lung adenocarcinoma cells by using Matrigel-coated transwell chambers. The results showed that the numbers of cells that crossed the Matrigel-coated filter membrane were significantly increased in the miR-7977 mimic groups compared to those in negative control groups after $48 \mathrm{~h}$ (Figure 4D), while upregulation of miR-7975 did not affect cellular invasion. All these data confirmed that miR-7977 was 

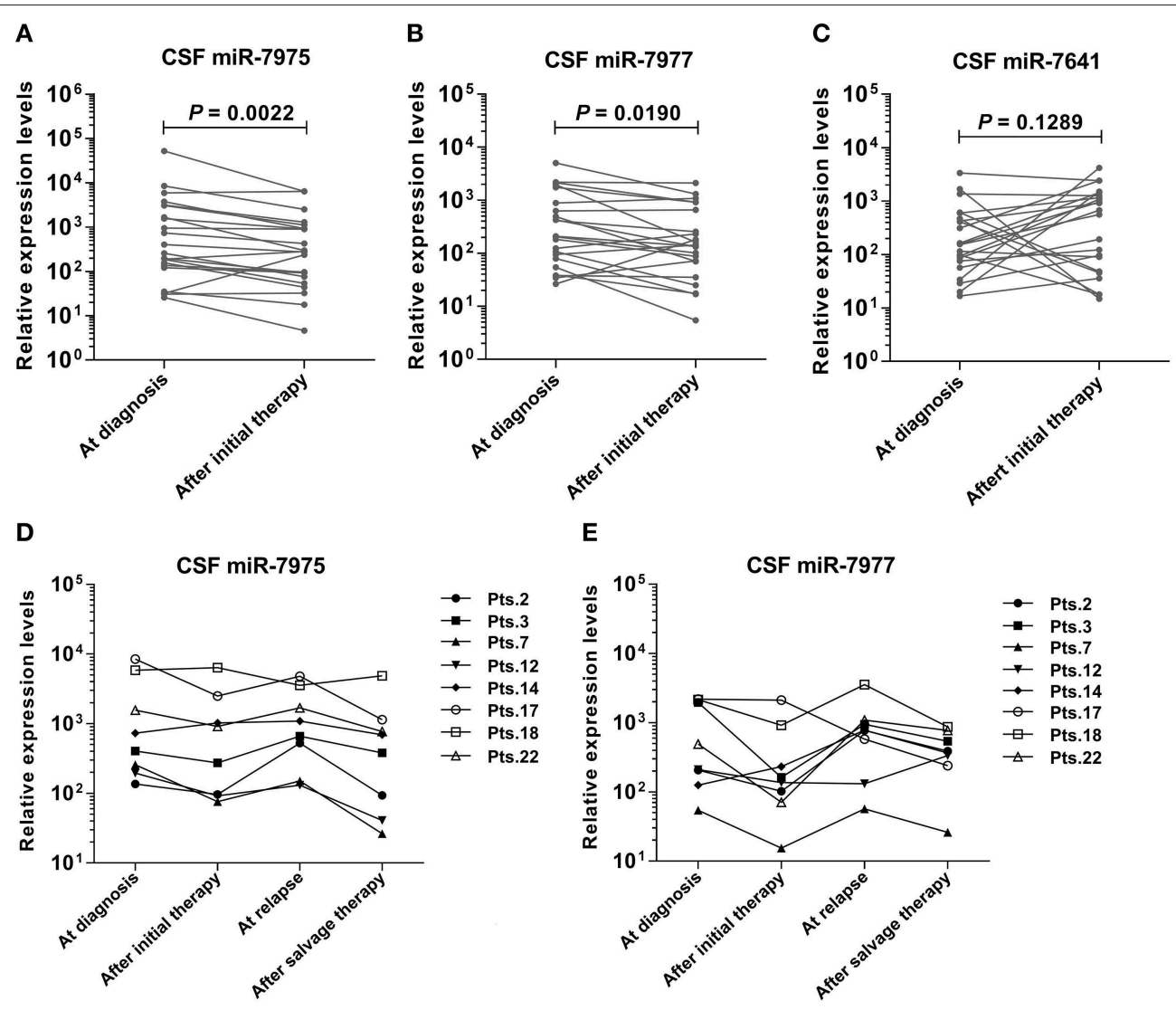

FIGURE 3 | Identification of specific CSF miRNAs expression through the course of LM. RELs of miRNA were compared between matched CSF samples from 22 LM patients at diagnosis and after initial LM-directed therapy. Compared with the levels at diagnosis, CSF miR-7975 (A) and miR-7977 (B) were significantly down regulated in LM patients after initial efficacious therapy, while CSF miR-7641 (C) was not. Then miR-7975 and miR-7977 in sequential CSF samples from 8 LM patients collected at four time points: at diagnosis, after initial therapy, at relapse and after salvage therapy were analyzed. Longitudinal REL data of both CSF miR-7975 (D) and miR-7977 (E) in 6 out of 8 LM patients correlated well with the clinical courses of disease, decreasing after initial therapy, rising during relapse, and again returning to lower levels after salvage therapy. Lines, matched samples. RELs of miRNAs (y-axis) are normalized to cel-miR-39. A value of $P<0.05$ was regarded as statistically significant. RELs, relative expression levels; LM, leptomeningeal metastasis.

a key regulator of proliferation, migration, and invasion in lung adenocarcinoma.

\section{Target Gene Prediction and Function Analysis of miR-7977}

The target genes of miR-7977 were predicted using TargetScan, miRDB, and miRTarbase online analysis tools. A total of 385 overlapping genes in any two databases was identified (Figure 5A). Then, GO function annotation analyses including biological process, cellular component, and molecular function were performed on these potential target genes (Figure 5B). It was worth noting that the GO biological process terms were mainly enriched in cell migration, regulation of cell migration, and regulation of cell differentiation, and localization of cell. Subsequently, we conducted KEGG pathway enrichment analysis to further analyze the enriched pathways of these target genes. As shown in Figure 5C, the enriched KEGG pathways included chemokine signaling pathway, cell adhesion molecules, gap junction, Wnt signaling pathway, pathways in cancer, tight junction, Jak-STAT signaling pathway, and mitogen-activated protein kinase (MAPK) signaling pathway. In all the three databases, there were four overlapping target genes including CCL22, STK4, HSPA1B, and ACTR2, which were associated with cell migration, chemokine signaling pathway, and MAPK signaling pathway.

\section{DISCUSSION}

LM is a typically late complication of solid tumors. Diagnosis and monitoring of LM are challenging. Additionally, it implies a poor prognosis and limited treatment options (3). Therefore, study biomarkers and mechanisms of development in LM are of great significance for improving the prognosis of LM and provide a new target for design of good therapy. In the present study, we systematically investigated the miRNA profiles of a relatively large number of CSF samples from LM patients with lung adenocarcinoma and non-LM patients. It demonstrated for the first time that three CSF miRNA (miR-7975, miR-7977, and 


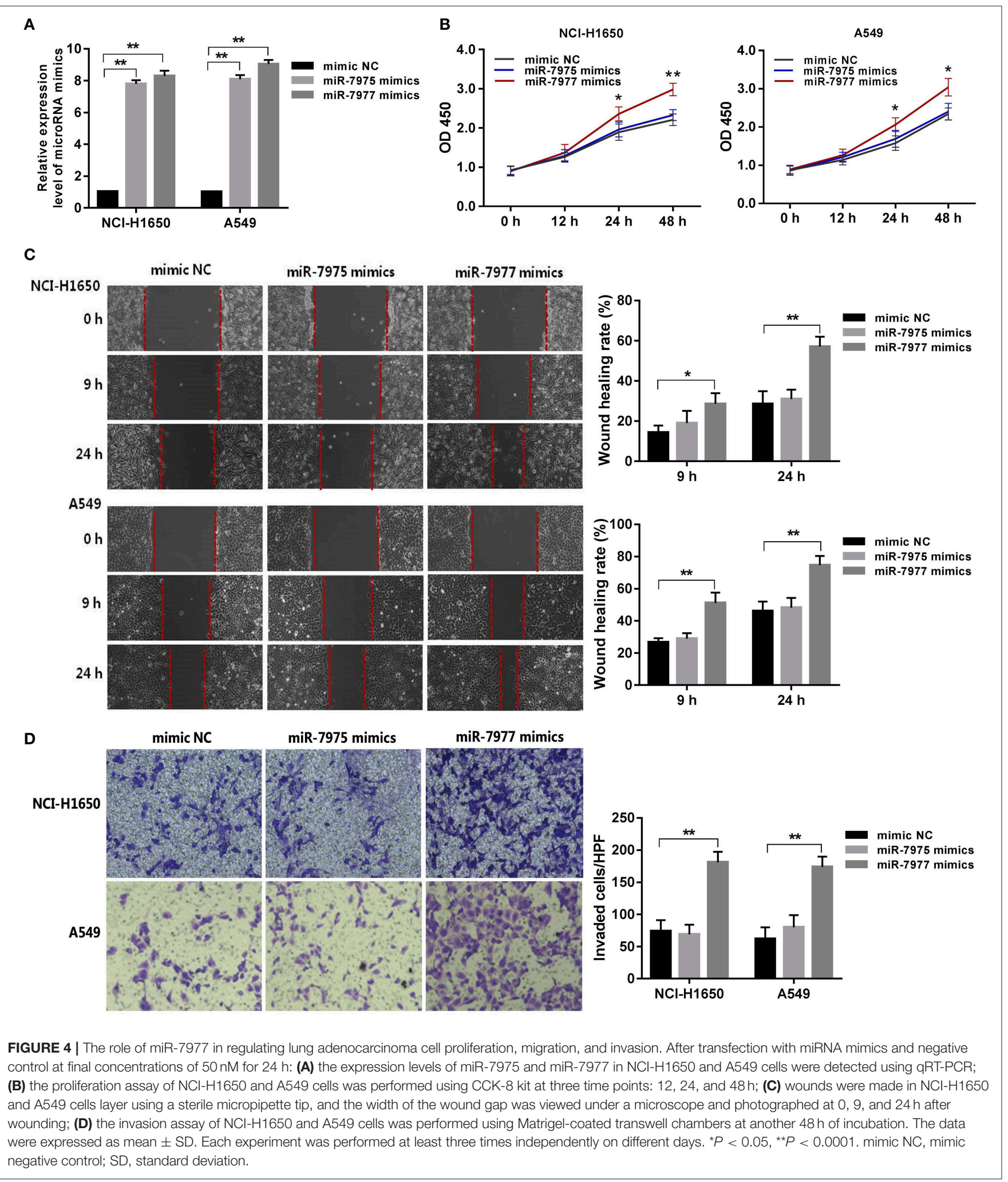

miR-7641) levels were higher in lung adenocarcinoma patients with LM than those without LM. The combined three miRNAs exhibited optimal diagnostic performance, suggesting that they may be potential diagnostic biomarkers for LM. Furthermore, the dynamic change in expression level of these CSF miRNAs at diagnosis, after initial therapy, at relapse, and after salvage therapy showed that the expression levels of CSF miR-7975 and miR-7977 were concordant with the course of disease, 

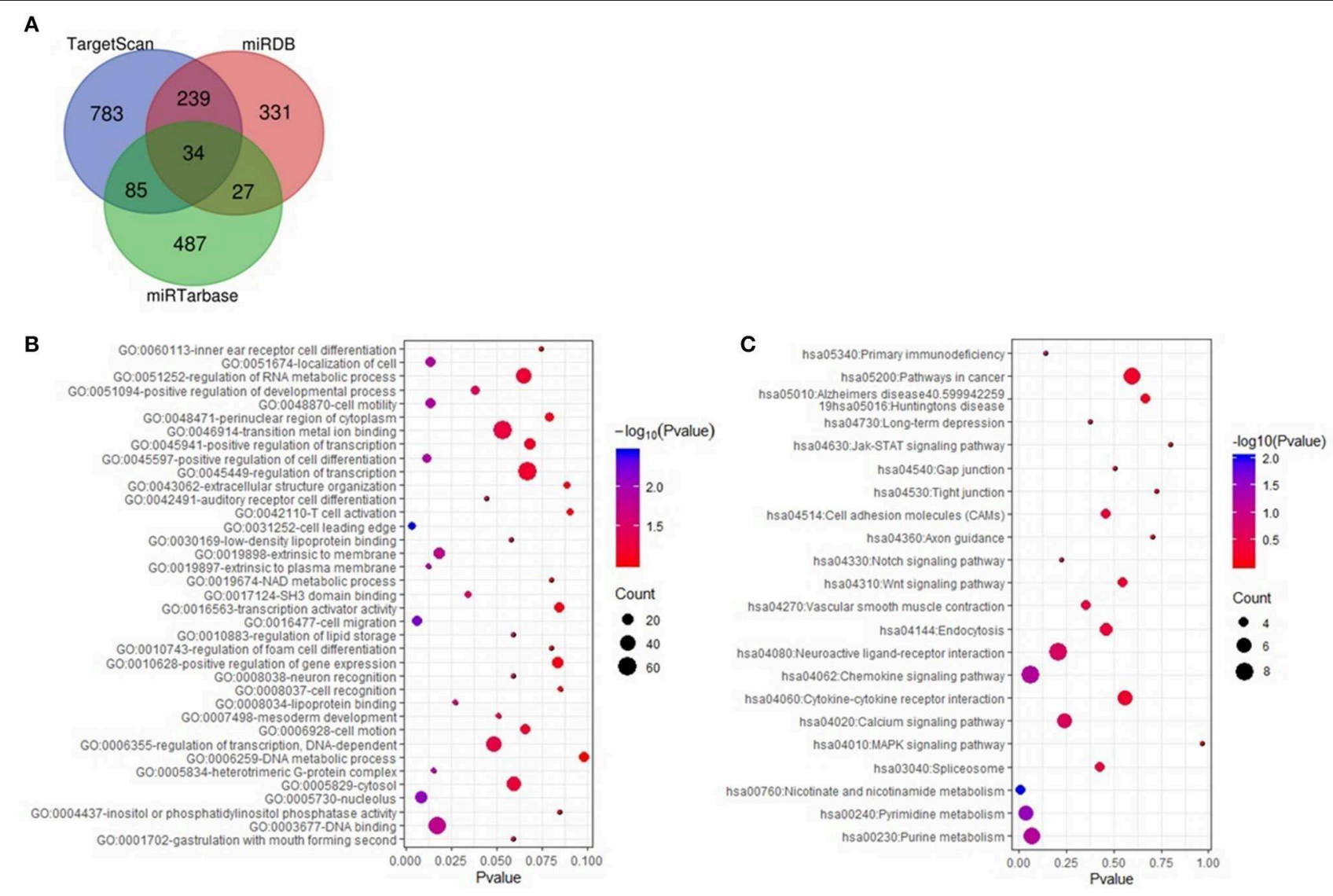

FIGURE 5 | The targeted genes of miR-7977 prediction and function anlysis. (A) The overlapping targeted genes were predicted using TargetScan, miRDB and miRTarbase online analysis tools; (B) The enriched GO annotation for target genes of miR-7977 including biological process, cellular component and molecular function; (C) The enriched KEGG pathways for target genes of miR-7977. The gene count $\geq 3$ were set as the cut-off criteria.

which indicated the application value of the two miRNAs for monitoring LM course. In addition, the results of both experiments on cell biological functions and bioinformatics analysis suggested that miR-7977 is a key factor for LM in lung adenocarcinoma, which develops a new way for exploring the mechanism of LM.

It is essential to make early diagnosis for efficacious treatment and improvement of disease prognosis, because LM represents a devastating cancer complication. Several researches on LM have evaluated the diagnostic accuracy of CSF cytology and magnetic resonance imaging (MRI) methods $(17,18)$. However, both of these methods are highly examiner-dependent and have limitations of inter-reader variability and non-specific findings, which prompted studies evaluating other CSF biomarkers (1923). The findings of our study were that CSF miR-7975, miR7977, and miR-7641 could discriminate LM patients from non-LM subjects. It was worth noting that the combination of the three CSF miRNAs had a significant diagnostic value for LM and yielded an AUC of 0.960 in ROC analysis. The data of this study strongly indicates that the analysis of miRNA in CSF is a promising approach for exploring minimally invasive screening examinations for LM. Since repeated lumbar puncture for CSF cytology examination is unacceptable for brain metastasis patients with suspected LM, these findings are of great importance, especially to differentiate LM patients from brain metastasis patients at the time of initial CSF examination.

LM patients frequently suffer from disease relapse or progression. So far, there is still no definite biomarker for reflecting disease course of LM. Generally, if the development of the disease during different stages has the same pathologic process, ideal diagnostic biomarkers can be used for disease monitoring (24). A previous report has suggested using miRNA detection in CSF to monitor the course of primary CNS lymphoma (25). In this study, we addressed CSF miRNA levels over time of individual LM patients as potential markers for the purpose of monitoring disease course. In our pilot study, longitudinal detections of CSF miRNA levels in LM patients were performed, the results of which indicate that the differential expression of CSF miR-7975 and miR-7977 was correlated with the LM disease course. Although observations here are based on a small number of cases, our study provides the rationale for future investigations of CSF miRNAs as biomarkers for monitoring disease course of LM patients in larger cohorts. 
The identification of specific CSF miRNAs in this study not only provides a new method for diagnosing and monitoring LM but also develops a new way for exploring the mechanism of LM. The molecular mechanism of LM is still elusive, which may be the main obstacle to seeking efficacious treatment. Currently, efforts to better understand the molecular mechanism of LM have been severely limited by the difficulties in isolating tumor cells from CSF as well as characterizing them. Increasing evidence emerging from preclinical models of different tumor types clearly indicates that specific miRNAs play a functional role in different steps of the metastatic cascade (26). In our study, CSF miR-7975 and miR-7977 are up-regulated specifically in patients of LM from lung adenocarcinoma, but not in those of brain metastases from lung adenocarcinoma and non-cancers. Moreover, both of them have been confirmed to be closely related with the course of LM disease. Although the biologic significance of these specific CSF miRNAs in LM patients needs to be established, one of them has already been associated with malignant diseases. MiR-7977 in extracellular vesicles has been demonstrated to induce failure of normal hematopoiesis via its target gene poly $(\mathrm{rC})$ binding protein 1 (PCBP1) in hematologic malignancies (27). In this study, we found that overexpression of miR-7977 promoted proliferation, invasion, and migration of lung adenocarcinoma cells. Furthermore, GO function analyses showed that the targeted genes of miR-7977 were mainly involved in regulation of cell migration and cell differentiation. Based on the existing literature and our experimental results, we speculate that miR-7977 may have a function of oncogene in LM. The increase of miR-7977 expression may trigger the activation of proliferation, invasion, and migration, which were related cancer metastasis mechanisms, and promote the occurrence of LM. It provides a theoretical basis for revealing the possible mechanism of LM.

In addition, we found that the KEGG pathways of miR7977 targeted genes included tight junction, gap junction, and other abnormal signaling pathways including the Wnt signaling pathway, Jak-STAT signaling pathway, and MAPK signaling pathway. One of the main patterns of LM is believed to occur via hematogenous route, implying that cancer cells reach the brain barrier and invade the space of CSF flow. Tight junctions have become a key factor in the studies on integrity of brain barrier including blood-brain barrier (BBB) and blood-cerebrospinal fluid barrier (BCSFB) during CNS metastasis. A previous study has confirmed that disruption of the tight junctions of the $\mathrm{BBB}$ is an important link in the development of brain metastasis $(28,29)$. Since BCSFB plays a vital role during the occurrence of LM, we speculate that the overexpression of miR-7977 may allow cancer cells to transmigrate through the BCSFB by regulating tight junctions. In addition, the four overlapping target genes of miR-7977 (CCL22, STK4, HSPA1B, and ACTR2) in all three databases were reported to have a key role in cancer formation and metastasis. Studies have shown that these genes are involved in the growth, invasion, and metastasis of a variety of tumors, and that they play a key role in tumorrelated molecular mechanisms (30-33). Furthermore, abnormal signaling pathways also play crucial roles in the development of cancer metastasis. Accumulating evidence has demonstrated that activation of MAPK signaling pathway, Jak-STAT signaling pathway, and Wnt signaling pathway is important in cancer progression (34-36). Therefore, it is needed to perform further molecular investigations to confirm these predictions, and it can provide a new perspective in exploring the mechanism of LM and a new intervention method in LM treatment.

There are several limitations of this study. First, the CSF sample size was not large enough in the microarray analysis. Second, our study indicated that the specific CSF miRNAs have potential value in diagnosis and monitoring of LM. However, all the patients enrolled in this study were from our hospital. Potential drawbacks such as selection bias may occur. Further validation of the identified miRNAs in a larger independent population from multiple cancer centers is necessary before they can be put in a clinical application. Third, only experiments on biological functions in vitro and bioinformatics analysis of miR-7977 were performed in this study. Research on detailed molecular mechanisms that miR-7977 promotes the occurrence of LM through regulating targeted genes is lacking. Therefore, it is required to perform future investigations with larger clinical samples and corresponding experiments.

\section{CONCLUSIONS}

In conclusion, we have successfully identified three LMassociated miRNAs (miR-7975, miR-7977, and miR-7641) based on microarray screening and qRT-PCR validation. Moreover, this study, if confirmed in prospective clinical trials, indicates that these miRNA signatures could be a significant tool to diagnose and monitor LM. In addition, the experiments in vitro and bioinformatic analysis suggested that miR-7977 plays a key role in the development of LM, which reveals a novel pathway to exploration of underlying mechanisms of LM, and provides a promising target in treating LM patients. CSF miRNAs are potentially of high worth for LMrelated studies; however, much work still needs to be done to shepherd findings from scientific research into advanced clinical applications.

\section{DATA AVAILABILITY STATEMENT}

The datasets generated for this study can be found in tNCBI Gene Expression Omnibus (GEO) through accession number GSE125193.

\section{ETHICS STATEMENT}

This study was approved by the Institutional Ethics Review Board of the First Hospital of Jilin University, Changchun, China, and was performed in accordance with the Declaration of Helsinki.

\section{AUTHOR CONTRIBUTIONS}

ZP, GY, GZ, and YC designed the study. ZP and GY wrote the manuscript. ZP, GY, TJ, and $\mathrm{HH}$ performed the experiments 
and statistical analysis of the data. TJ and PG collected clinical samples and clinical data of patients. All authors read and approved the final manuscript.

\section{FUNDING}

This work was supported by grants from the Jilin Provincial Education Department 13th Five-Year Science and Technology Project (JJKH20170850KJ to ZP and JJKH20180191KJ to YC), National Natural Science Foundation of China (81502753 to GY and 81772684 to GZ), the S\&T Development Planning Program of Jilin Province (20190201004JC to ZP, 20180101152JC to GZ, 20180520133JH to GY), and the Interdisciplinary

\section{REFERENCES}

1. Gleissner B, Chamberlain MC. Neoplastic meningitis. Lancet Neurol. (2006) 5:443-52. doi: 10.1016/S1474-4422(06)70443-4

2. Grossman SA, Krabak MJ. Leptomeningeal carcinomatosis. Cancer Treat Rev. (1999) 25:103-19. doi: 10.1053/ctrv.1999.0119

3. Pan Z, Yang G, Cui J, Li W, Li Y, Gao P, et al. A pilot phase 1 study of intrathecal pemetrexed for refractory leptomeningeal metastases from non-small-cell lung cancer. Front Oncol. (2019) 9:838. doi: 10.3389/fonc.2019.00838

4. Chamberlain M, Junck L, Brandsma D, Soffietti R, Ruda R, Raizer J, et al. Leptomeningeal metastases: a RANO proposal for response criteria. Neuro Oncol. (2017) 19:484-92. doi: 10.1093/neuonc/now183

5. Wang N, Bertalan MS, Brastianos PK. Leptomeningeal metastasis from systemic cancer: review and update on management. Cancer. (2018) 124:2135. doi: 10.1002/cncr.30911

6. Le Rhun E, Weller M, Brandsma D, Van den Bent M, de Azambuja E, Henriksson R, et al. EANO-ESMO clinical practice guidelines for diagnosis, treatment and follow-up of patients with leptomeningeal metastasis from solid tumours. Ann Oncol. (2017) 28(suppl. 4):48499. doi: 10.1093/annonc/mdx221

7. Kumar Shah B, Pak I, Budhathoki N, Buker K. Targeted therapy for leptomeningeal metastases in non-small cell lung cancer changing treatment paradigms. Chin Journal Cancer Res. (2017) 29:535-42. doi: 10.21147/j.issn.1000-9604.2017.06.08

8. Bartel DP. MicroRNAs: genomics, biogenesis, mechanism, and function. Cell. (2004) 116:281-97. doi: 10.1016/S0092-8674(04)00045-5

9. Shukla GC, Singh J, Barik S. MicroRNAs: processing, maturation, target recognition and regulatory functions. Mol Cell Pharmacol. (2011) 3:83-92.

10. Rink C, Khanna S. MicroRNA in ischemic stroke etiology and pathology. Physiol Genomics. (2011) 43:521-8. doi: 10.1152/physiolgenomics.00158.2010

11. Iorio MV, Croce CM. MicroRNA dysregulation in cancer: diagnostics, monitoring and therapeutics. A comprehensive review. EMBO Mol Med. (2012) 4:143-59. doi: 10.1002/emmm.201100209

12. De Mattos-Arruda L, Mayor R, Ng CK, Weigelt B, Martinez-Ricarte F, Torrejon $\mathrm{D}$, et al. Cerebrospinal fluid-derived circulating tumour DNA better represents the genomic alterations of brain tumours than plasma. Nat Commun. (2015) 6:8839. doi: 10.1038/ncomms9839

13. Yue X, Lan F, Hu M, Pan Q, Wang Q, Wang J. Downregulation of serum microRNA-205 as a potential diagnostic and prognostic biomarker for human glioma. J Neurosurg. (2016) 124:122-8. doi: 10.3171/2015.1.JNS141577

14. Lin Y, Chen F, Shen L, Tang X, Du C, Sun Z, et al. Biomarker microRNAs for prostate cancer metastasis: screened with a network vulnerability analysis model. J Transl Med. (2018) 16:134. doi: 10.1186/s12967-018-1506-7

15. Huang da W, Sherman BT, Lempicki RA. Bioinformatics enrichment tools: paths toward the comprehensive functional analysis of large gene lists. Nucleic Acids Res. (2009) 37:1-13. doi: 10.1093/nar/gkn923
Innovation Project of the First Hospital of Jilin University (JDYYJC001 to YC).

\section{ACKNOWLEDGMENTS}

The authors thank Sinotech Genomics Corporation for helping in microarray experiments. They also thank all the individuals who participated in this study.

\section{SUPPLEMENTARY MATERIAL}

The Supplementary Material for this article can be found online at: https://www.frontiersin.org/articles/10.3389/fonc. 2020.00387/full\#supplementary-material

16. Huang da W, Sherman BT, Lempicki RA. Systematic and integrative analysis of large gene lists using DAVID bioinformatics resources. Nat Protoc. (2009) 4:44-57. doi: 10.1038/nprot.2008.211

17. Chamberlain MC. Leptomeningeal metastases in the MRI era. Neurology. (2011) 76:200. doi: 10.1212/WNL.0b013e3181fac738

18. Freilich RJ, Krol G, DeAngelis LM. Neuroimaging and cerebrospinal fluid cytology in the diagnosis of leptomeningeal metastasis. Ann Neurol. (1995) 38:51-7. doi: 10.1002/ana.410380111

19. Wang P, Piao Y, Zhang X, Li W, Hao X. The concentration of CYFRA 21-1, NSE and CEA in cerebro-spinal fluid can be useful indicators for diagnosis of meningeal carcinomatosis of lung cancer. Cancer Biomark. (2013) 13:123-30. doi: 10.3233/CBM-130338

20. Herrlinger U, Wiendl H, Renninger M, Forschler H, Dichgans J, Weller M. Vascular endothelial growth factor (VEGF) in leptomeningeal metastasis: diagnostic and prognostic value. $\mathrm{Br} J$ Cancer. (2004) 91:219-24. doi: 10.1038/sj.bjc.6601953

21. Stockhammer G, Poewe W, Burgstaller S, Deisenhammer F, Muigg A, Kiechl S, et al. Vascular endothelial growth factor in CSF: a biological marker for carcinomatous meningitis. Neurology. (2000) 54:16706. doi: 10.1212/WNL.54.8.1670

22. Sindeeva OA, Verkhovskii RA, Sarimollaoglu M, Afanaseva GA, Fedonnikov AS, Osintsev EY, et al. New frontiers in diagnosis and therapy of circulating tumor markers in cerebrospinal fluid in vitro and in vivo. Cells. (2019) 8:E1195. doi: 10.3390/cells8101195

23. Zhang A, Wang C, Lu H, Chen X, Ba Y, Zhang C, et al. Altered serum Microrna profile may serve as an auxiliary tool for discriminating aggressive thyroid carcinoma from nonaggressive thyroid cancer and benign thyroid nodules. Dis Mark. (2019) 2019:3717683. doi: 10.1155/2019/37 17683

24. Sheinerman KS, Umansky SR. Circulating cell-free microRNA as biomarkers for screening, diagnosis and monitoring of neurodegenerative diseases and other neurologic pathologies. Front Cell Neurosci. (2013) 7:150. doi: 10.3389/fncel.2013.00150

25. Taillibert S, Chamberlain MC. Leptomeningeal metastasis. Handb Clin Neurol. (2018) 149:169-204. doi: 10.1016/B978-0-12-811161-1. 00013-X

26. White NM, Fatoohi E, Metias M, Jung K, Stephan C, Yousef GM. Metastamirs: a stepping stone towards improved cancer management. Nat Rev Clin Oncol. (2011) 8:75-84. doi: 10.1038/nrclinonc.2010.173

27. Horiguchi H, Kobune M, Kikuchi S, Yoshida M, Murata M, Murase $\mathrm{K}$, et al. Extracellular vesicle miR-7977 is involved in hematopoietic dysfunction of mesenchymal stromal cells via poly(rC) binding protein 1 reduction in myeloid neoplasms. Haematologica. (2016) 101:43747. doi: 10.3324/haematol.2015.134932

28. Jia W, Martin TA, Zhang G, Jiang WG. Junctional adhesion molecules in cerebral endothelial tight junction and brain metastasis. Anticancer Res. (2013) 33:2353-9. 
29. Huber JD, Egleton RD, Davis TP. Molecular physiology and pathophysiology of tight junctions in the blood-brain barrier. Trends Neurosci. (2001) 24:71925. doi: 10.1016/S0166-2236(00)02004-X

30. Sun Y, Shang Y, Ren G, Zhou L, Feng B, Li K, et al. Coronin3 regulates gastric cancer invasion and metastasis by interacting with Arp2. Cancer Biol Ther. (2014) 15:1163-73. doi: 10.4161/cbt.29501

31. Song F, Wei M, Wang J, Liu Y, Guo M, Li X, et al. Hepatitis B virus-regulated growth of liver cancer cells occurs through the microRNA-340-5p-activating transcription factor 7-heat shock protein A member 1B axis. Cancer Sci. (2019) 110:1633-43. doi: 10.1111/cas.14004

32. Peng $\mathrm{X}$, Ji C, Tan L, Lin S, Zhu $\mathrm{Y}$, Long $\mathrm{M}$, et al. Long noncoding RNA TNRC6C-AS1 promotes methylation of STK4 to inhibit thyroid carcinoma cell apoptosis and autophagy via Hippo signalling pathway. J Cell Mol Med. (2020) 24:304-16. doi: 10.1111/jcmm. 14728

33. Huang YH, Chang CY, Kuo YZ, Fang WY, Kao HY, Tsai ST, et al. Cancer-associated fibroblast-derived interleukin-1beta activates protumor C-C motif chemokine ligand 22 signaling in head and neck cancer. Cancer Sci. (2019) 110:2783-93. doi: 10.1111/cas. 14135

34. Li W, Yu KN, Bao L, Shen J, Cheng C, Han W. Non-thermal plasma inhibits human cervical cancer HeLa cells invasiveness by suppressing the
MAPK pathway and decreasing matrix metalloproteinase-9 expression. Sci Rep. (2016) 6:19720. doi: 10.1038/srep19720

35. Mullany LE, Herrick JS, Sakoda LC, Samowitz W, Stevens JR, Wolff RK, et al. MicroRNA-messenger RNA interactions involving JAKSTAT signaling genes in colorectal cancer. Genes Cancer. (2018) 9:232-46. doi: 10.18632/genesandcancer.177

36. Eyre R, Alferez DG, Santiago-Gomez A, Spence K, McConnell JC, Hart $\mathrm{C}$, et al. Microenvironmental IL1beta promotes breast cancer metastatic colonisation in the bone via activation of Wnt signalling. Nat Commun. (2019) 10:5016. doi: 10.1038/s41467-019-12807-0

Conflict of Interest: The authors declare that the research was conducted in the absence of any commercial or financial relationships that could be construed as a potential conflict of interest.

Copyright (c) 2020 Pan, Yang, He, Gao, Jiang, Chen and Zhao. This is an open-access article distributed under the terms of the Creative Commons Attribution License (CC $B Y)$. The use, distribution or reproduction in other forums is permitted, provided the original author(s) and the copyright owner(s) are credited and that the original publication in this journal is cited, in accordance with accepted academic practice. No use, distribution or reproduction is permitted which does not comply with these terms. 